\title{
Evaluation of Indeterminate Tomato (Solanum lycopersicum L.) Genotypes for Growth and Yield Traits under Polyhouse Condition
}

\author{
V. Premalakshmi, Sunanda Khuntia, P.R. Kamalkumaran and T. Arumugam \\ Department of Vegetable Crops, \\ HC \& RI, Tamil Nadu Agricultural University, Coimbatore - 641003, Tamil Nadu.
}

\begin{abstract}
A study was conducted during the period of June 2015 to January 2017 at college orchard of Tamil Nadu Agricultural University, Coimbatore with an objective to evaluate tomato (Solanum lycopersicum L.) genotypes suitable for polyhouse condition. Fifty one genotypes received from diverse agro climatic regions were used for evaluation of twenty characters in a randomized block design with two replications. The genotypes were assessed for plant height, days to first flowering, number of flowers per truss, number of fruits per cluster, number of fruits per plant, fruit setting percentage, number of harvest, individual fruit weight and yield per plant. The analysis of variance showed that there existed significant differences among the genotypes with all character tested. Among the genotypes, plant height ranged from 84.0 (IIVR EC 620464) to $476.0 \mathrm{~cm}$ (NBPGR HYD EC 165700). Early flowering was recorded in IIVR PB Kaghri (26.88 days). Number of flowers per truss ranged from 4.00 (Punjab Gourav) to 8.65 (IIHR 2042). The highest number of fruits per cluster was recorded in IIHR 2042 (7.61). Number of fruits per plant ranged between 5.00 in Punjab Gourav and 48.50 in NBPGR HYD IC 249514.The individual fruit weight ranged from 3.50 to $125.50 \mathrm{~g}$ in NBPGR HYD IC 249514 and in Pant Polyhouse Hybrid Tomato1 respectively. Yield per plant ranged from $0.20 \mathrm{~kg}$ (NBPGR HYD EC 145057) to $3.63 \mathrm{~kg}$ (IIVR EC 521038). From the study it was concluded that the tomato genotypes NBPGR HYD EC 165700 $(476.0 \mathrm{~cm})$ IIVR EC $521038(3.63 \mathrm{~kg})$ and IIHR $2042(2.36 \mathrm{~kg})$ could be most promising in terms of growth and yield under poly house condition.
\end{abstract}

Key words : Tomato, Intermediate genotypes, Polyhouse cultivation

Tomato (Solanum lycopersicum L. $2 \mathrm{n}=2 \mathrm{x}=24$ ) is one of the most important member of solanaceae family and widely grown in many countries across the globe. It is originated and domesticated in Andean region of South America and in Mexico. Today, it is the second largest cultivated vegetable crop in the world after potato. In India, tomato is being cultivated in an area of 0.86 million ha with the production of 1.87 million MT and the productivity of $21.2 \mathrm{t} \mathrm{ha}^{-1}$ (NHB database, 2015). Tomato fruit contains as much as 93 to $94 \%$ water and it has high nutritive value, being a good source of minerals, acids and vitamins (A, B and C). Tomato fruit provides $3.4 \%$ of total sugars, $4.7 \%$ of total solids, 15 to $30 \mathrm{mg}^{100 \mathrm{~g}^{-1}}$ of ascorbic acid, $7.5 \mathrm{mg} / 100 \mathrm{ml}$ of titrable acidity and 20 to $50 \mathrm{mg}$ $1100 \mathrm{~g}$ of lycopene (Chadha, 2012). The aim of protected cultivation is to achieve independence of climate and weather and to allow crop production in areas where the natural environment limits or prohibits plant growth. Tomato is a high value vegetable crop for off season and main season production under polyhouse. The differences are observed in the production and productivity of polyhouse bred tomato (350 to $450 \mathrm{t} \mathrm{ha}^{-1}$ ) under polyhouse (AICVIP annual report 2002 - 2004). The benefits of cultivation of tomato in protected

*Corresponding author’s email: premavelu@rediffmail.com structure is to prevent the crop from excessive solar radiation, improving the thermal climate, sheltering from wind and hail, exclusion of birds and insecttransmitted virus diseases. It also helps to alter the light quality to a varying extent and might also change other environmental conditions. Considering the potentiality of tomato under polyhouse, there is a need for improvement and to develop new varieties suited to polyhouse conditions. A thorough knowledge regarding the amount of genetic variability existing for various characters are essential for initiating the crop improvement programme.

\section{Material and Methods}

The research was conducted at college orchard, Department of Vegetable crops, Horticulture College and Research Institute, Tamil Nadu Agricultural University during 2015 -2017. Fifty one genotypes were collected from diverse agro climatic zones of India viz., IIHR(Indian Institute of Horticultural Research), Bangalore. NBPGR (National Bereau of Plant Genetics Resources), Hyderabad. IIVR (Indian Institute of Vegetable Research), Varanasi. PAU (Punjab Agricultural University), Ludhiana. GBPUA\&T (Govind Ballabh Pant University of Agriculture and Technology), Pantnagar. The experiment was laid out in a randomized complete block design (RBD) 
with two replications under polyhouse. The seedlings were raised in protray and maintained under shade net house. The nursery area of slanting slope of $2 \%$ was covered with 50 per cent shade net and the sides were covered using 40/50 mesh insect proof nylon net. The raised beds of 1 meter width and convenient length were prepared and above the beds the HDPV pipes were placed in $2 m$ interval for further protection with polythene sheets during rainy months. The protrays of 98 cells $(54 \times 27 \mathrm{~cm})$ of $3.5 \mathrm{~cm}$ diameter and $0.8 \mathrm{~mm}$ thickness were used for raising tomato seedlings. Seeds were sown in pro trays filled with cocopeat medium at one seed per cell. Apprently healthy 25-27 days old seedlings were transplanted in the experimental field following $60 \times 60 \mathrm{~cm}$ spacing Five plants were randomly selected per accession per replication for recording observations and the mean values worked out.

\section{Results and Discussion}

Analysis of variance revealed significant differences among the 51 genotypes with respect to

Table 1. Mean performance of 51 tomato genotypes on growth contributing characters

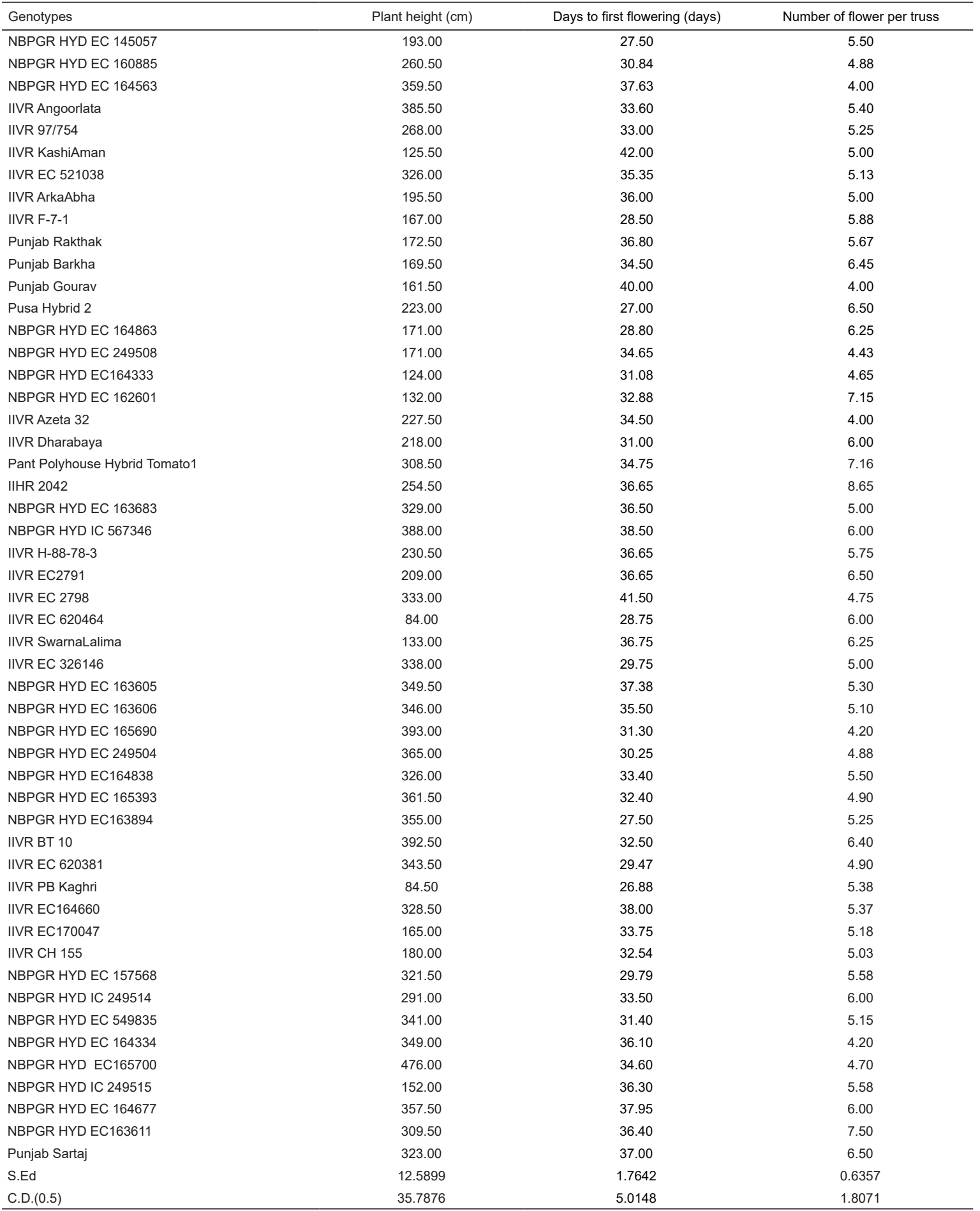


plant height $(\mathrm{cm})$, days to first flowering, number of flowers per truss, number of fruits per cluster, number of fruits per plant, fruit setting percentage (\%), individual fruit weight ( $\mathrm{gm})$, and yield per plant $(\mathrm{kg})$. Mean sum of squares were found to be significant for all treatment because all genotypes were genetically different from each other.

Table 2. Mean performance of 51 tomato genotypes on yield contributing characters

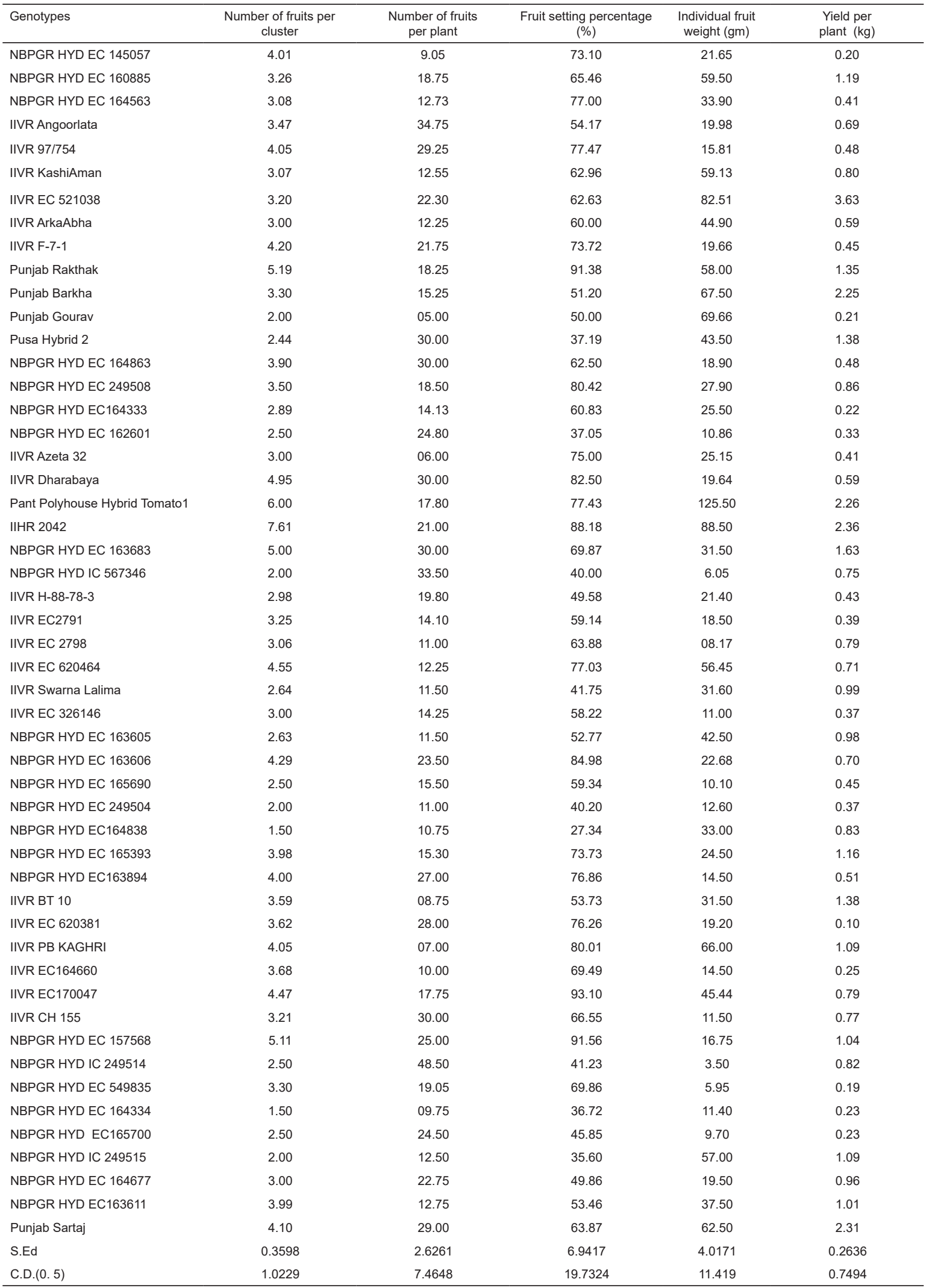


Mean performance of hybrids with respect to plant growth and yield and yield are presented in Table 1 and 2. Observations on plant height showed that NBPGR HYD EC 165700 had recorded the highest mean plant height of $476.00 \mathrm{~cm}$ followed by NBPGR HYD EC $165690(393.0 \mathrm{~cm})$, whereas the lowest mean plant height was observed in the genotype IIVR EC $620464(84.00 \mathrm{~cm})$. Increase in plant height might be due to the favourable micro-climate inside the polyhouse, enhancing the growth and development by increasing the role of plant response to lower light intensity inside the polyhouse resulting in cell elongation and increased internodal length leading to an increase in plant height. The present study also revealed that days to first flowering ranged from 26.88 to 42.00 days among the genotypes. PB Kaghri showed the earliest ( 26.88 days) and IIVR KashiAman was the last to flower (42.00 days). Earliness is a desirable character and might be due to the capacity of the genotype to make available assimilates to the reproductive site during the phase of flower initiation coinciding with favourable polyhouse condition. This is in agreement with the study of Prema et al. (2011) who worked with cherry tomato. IIHR 2042 recorded the highest number of flowers per truss of (8.65) followed by NBPGR HYD EC 163611 (7.50) and NBPGR HYD EC 164563, Punjab Gourav. The significant variation in number of flowers per truss among the tomato genotypes might be due to the inherent genetic potential of the genotypes to produce flower at the controlled environmental condition inside the polyhouse. For number of fruits per plant, the genotype IIHR 2042 recorded the highest number of fruits per cluster (7.60) followed by Pant Polyhouse Hybrid Tomato 1 (6.00) and the lowest number of fruits per cluster was observed in Punjab Gourav, NBPGR HYD IC 567346, NBPGR HYD EC 249504 and NBPGR HYD IC 249515 (2.00). Better pollination, which leads to more number of fruit set per cluster. However, as per the studies of Prema et al. (2011), the number of fruits per cluster was maximum in tomato genotype Stupice Harry and EC-1 (7.13) followed by Broad Riper (6.46) among the six cherry tomato genotypes tested under open field condition. NBPGR HYD IC 249514 recorded the highest number of fruits per plant of 48.50 followed by the genotype IIVR Angoorlata (34.75), NBPGR HYD IC 567346 (33.50) whereas, the lowest number of fruits per plant was recorded in the genotype Punjab Gourav (5.00). More number of fruits might be due to genetic makeup of the genotypes and more number of fruiting clusters. This agrees with the results of Lekshmi and Celine (2015) and Cheema et al. (2013). IIVR EC 170047 recorded the highest fruit setting percentage $(93.10 \%)$ which was found to be statistically on par with NBPGR HYD EC 157568 (91.56\%), Punjab Rakthak (91.38\%) whereas the lowest fruit setting percentage was recorded with NBPGR HYD EC164838 (27.34\%). The variation in fruit setting percentage might be due to the varied response of genotype to growing environment and genetic potential. This results are in agreement with that of Hazarika and Phookan (2005) and Sharma and Singh (2015). Arora et al. (2006) also reported variations in fruit setting percentage due to variation in pollen release under fluctuating environmental condition. The mean individual fruit weight ranged from 3.50 to $125.50 \mathrm{~g}$ (Table2). Pant Polyhouse Hybrid Tomato 1 recorded the highest individual fruit weight of $125.50 \mathrm{gm}$ followed by IIHR $2042(88.50 \mathrm{gm})$ and IIVR EC 521038 (82.51gm). The lowest individual fruit weight was recorded in NBPGR HYD IC 249514 (3.50gm). Less number of fruits per plant might be a reason for higher fruit weight as it could result in higher accumulation of assimilates in the fruit. In the present studies, the highest yield per plant was recorded in IIVR EC $521038(3.63 \mathrm{~kg})$ followed by IIHR $2042(2.36 \mathrm{~kg})$ and Punjab Sartaj $(2.31 \mathrm{~kg})$ might be due to the genetic potential of the genotype, high fruit setting percentage, more number of fruits per plant, and higher fruit weight plant height in turn may increase the photosynthetic activity ultimately leading to higher yield per plant. These results are in conformity with the findings of Prema et al. (2011) and Singh et al. (2014), who reported that fruit setting percentage was directly related to yield in tomato. Lekshmi and Celine (2015) also reported that the expression of the plant yield was influenced by environmental condition in which the plant was grown.

\section{Conclusion}

There was high level of variability among the genotype, which could further be exploited for development of tomato hybrid suitable for poly house condition. NBPGR HYD EC 165700 recorded the highest mean plant height of $476.0 \mathrm{~cm}$ followed by NBPGR HYD EC 165690 (393.0 cm) and IIVR BT $(392.5 \mathrm{~cm})$. In case of earliness, IIVR PB Kaghri, IIVR Pusa Hybrid 2 and NBPGR HYD EC 145057 were found to be the most promising. The tomato genotypes IIVR EC 521038, IIHR 2042, Punjab Sartaj, Punjab Barkha were found to be promising in terms of yield per plant under polyhouse condition.

\section{References}

Arora, S.K., A.K. Bhatia, V.P. Singh and S.P.S. Yadav. 2006. Performance of indeterminate tomato hybrids under greenhouse conditions of north Indian plains. Haryana J. Hort. Sci., 35(4): 292-294.

Chadha, K.L. 2012. Tomato. In: Hand Book of Horticulture. Published by ICAR, New Delhi. 464-470.

Cheema, D.S., N.Singh and S.K Jindal. 2013. Evaluation of indeterminate tomato hybrids for fruit, yield and quality traits under net house and open field conditions. Veg. Sci., 40 (1): 45-49.

Lekshmi, S.L. and V.A. Celine. 2015. Genetic Diversity Studies in Tomato (Solanumlycopersicum L.) Under 
Protected Conditions.Int. J. of Curr.Microbiol.and Applied Sci., 5(4): 212-217.

NHB Data Base. 2015. National Horticulture Board Department of Agriculture and Co- operation, Government of India

Prema, G., K.M. Indiresh and H.M. Santhosha. 2011. Evaluation of cherry tomato (Solanumlycopersicum var. Cerasiforme) genotypes for growth, yield and quality traits. The Asian J. of Hort.,6(1):181-184.
Sharma, V.K. and T. Singh. 2015. Performance evaluation of tomato (Solanum Lycopersicum L.) hybrids for increased productivity under polyhouse conditions in temperate areas. J. Agric. and Crops. 1(6): 68-74.

Singh, M., N.P. Singh, S. Arya, B. Singh and Vaishali. 2014. Diversity analysis of tomato germplasm (Lycopersicumesculentum) using SSR markers. Int. J. of Agric. Sci and Res., 4(4): 41-48.

Received : November 16, 2017; Revised : December 19, 2017; Accepted : December 29, 2017 